How to be a compatibilist in metaphysics: The epistemic strategy

Massimiliano Carrara and Vittorio Morato

Department of Philosophy, Sociology, Education and Applied Psychology

Section of Philosophy

University of Padua

massimiliano. carrara@unipd.it

vittorio.morato@unipd.it

Office: +39 0498274749

Office: +390498274752 


\title{
How to be a compatibilist in metaphysics: The
}

\author{
epistemic strategy
}

\author{
Massimiliano Carrara and Vittorio Morato \\ Department of Philosophy, Sociology, Education \\ and Applied Psychology (FISPPA), University of Padua
}

\begin{abstract}
Conflicts between our best philosophical theories (BPTs) and our common beliefs are widespread. For example, if eliminativism is our BPT, then our BPT conflicts with common beliefs about the existence of middle-sized composite artifacts. "Compatibilism" is the name usually given to a theoretical attitude, according to which, in the case of a conflict between BPT and a common belief $\mathrm{P}$, we should try to find a reconciliation. The two major variants of compatibilism are "semantic compatibilism" (SC) and "cognitive compatibilism" (CC). According to SC, to be reconciled with BPT is the "real" version of the content of our ordinary assertions; according to CC, to be reconciled with BPT is the mental state we are "really" in while thinking P. In this paper, we present a new kind of compatibilism, epistemic compatibilism (EC). According to EC, to be reconciled with BPT is the explanation of why we believe that P. After presenting EC, we will argue that it fares better than SC and CC for at least two related reasons: EC does not rely on any form of what we call semantic or cognitive "recarving"; thus, EC avoids some sceptical problems that affect the other two versions of compatibilism.
\end{abstract}


Keywords. Meta-ontology, compatibilism in metaphysics, eliminativism, compatibilist semantics, epistemic compatibilism

\section{Introduction}

Conflicts between our best philosophical theories (BPTs) and our commonsense assertions and beliefs are widespread. For example, eliminativism conflicts with our commonsense ontology of composite objects, four-dimensionalism with our commonsense three-dimensionalism worldview, nominalism with our capacity to quantify and refer to abstract objects, Lewisian modal realism with the idea that what is possible for us it is true of us. ${ }^{1}$

Assume that eliminativism is our BPT and consider the following argument:

(1) According to eliminativism, there are no chairs.

(2) It is commonly believed that there are chairs.

(3) The proposition that there are chairs and the proposition that there are no chairs are inconsistent.

(4) Therefore: eliminativism and the common belief that there are chairs are incompatible.

The general form of this disagreement could be represented by the schema:

(Dis) 1. According to BPT, $\psi$.

2. It is commonly believed that $\phi$.

3. $\ulcorner\psi\urcorner$ and $\ulcorner\phi\urcorner$ are inconsistent.

4. Therefore: BPT and the common belief that $\phi$ are incompatible,

\footnotetext{
${ }^{1}$ A terminological note: by "eliminativism", here and in the rest of the paper, we have in mind a position in the metaphysics of material objects, according to which there are no middle-sized composite artifacts, not the position in the philosophy of mind, according to which mental states posited by common sense do not exist. See van Inwagen (1990) and Merricks (2001).
} 
where $\phi$ and $\psi$ are sentences, $\ulcorner\psi\urcorner$ and $\ulcorner\phi\urcorner$ the propositions they express, "according to $\mathrm{BPT}, \psi$ " simply means that $\psi$ is a consequence of $\mathrm{BPT}$ and $\phi$ and $\psi$ are inconsistent in the case that $\phi$ and $\psi$ cannot be true together. For the argument to go through, it is essential to implicitly assume that a theory and a belief are incompatible just in case their propositional content are inconsistent. As we will see, this assumption will be shown to be problematic.

Conflicts between BTPs and beliefs can be managed in at least two ways. According to what might be called the "pereat belief strategy", it is our beliefs that must go. After all, our BPTs are there just to clean up our common sense and to eradicate false recalcitrant beliefs. According to Quine (1948), for example, the fact that certain entities are assumed or dismissed by our BPT (preferably expressed in a first-order language) constitutes, basically alone, a good reason to abandon beliefs about such entities and a justification to endorse other beliefs compatible with the existential commitments of the BPT.

However, not every recalcitrant common belief counts as equal. Some of them regulate fundamental aspects of our worldview, conceptual abilities or inferential practices. In such a case, the contrast should be solved more cautiously. One should look for a reconciliation strategy, a strategy to reconcile recalcitrant common beliefs with BPTs.

In this paper, we will use the term "compatibilism" to refer to any attempt done in philosophy to reconcile such recalcitrant common beliefs with BPTs. There are various forms of compatibilism, but most of them belong to the following two kinds:

Semantic compatibilism BPT and $\phi$ are compatible (s-compatible), if it is shown that the proposition expressed by an ordinary utterance of " $\phi$ " is consistent with $\psi$.

Cognitive compatibilism BPT and $\phi$ are compatible (c-compatible), if it is shown that the mental state a subject $x$ is in when entertaining $\phi$ does not commit $x$ to some proposition inconsistent with $\psi$. 


\footnotetext{
${ }^{2}$ For example, Quine (1948), Yablo (1998), Kennedy and Stanley (2009).

${ }^{3}$ The distinction hermeneutic/revolutionary comes from Burgess (1983) and Burgess and Rosen (1997). Stanley (2001, p. 36) introduced the the term "hermeneutic fictionalism". See also Yablo (2001) and Kalderon (2005).

${ }^{4}$ For J. Stanley:
} 
Both kinds of compatibilism have something in common. They are both based on a methodological attitude that might be called "recarving": semantic compatibilism is based on a form of semantic recarving, according to which the proposition expressed by ordinary assertions is not (at least in some cases) what it appears to be. The proposition really expressed by "the average American has 2.3 children" is that the number of children divided by the number of Americans is 2.4. Cognitive compatibilism is based on a form of cognitive recarving, according to which the mental states we are in while entertaining a proposition are not what they appear to be. The mental state we are in while thinking about Sherlock Holmes is really one of pretense, not belief.

The aim of this paper is to present and defend a third kind of compatibilism, epistemic compatibilism:

Epistemic compatibilism (EC): BPT and $\phi$ are compatible (e-compatible) when there is an explanation showing why it is believed that $\phi$ is consistent with $\psi .^{5}$

According to epistemic compatibilism, to be compatible with BPTs it is not the recarved content of our ordinary assertions or the recarved mental states, but the explanation of such beliefs. What is needed to obtain a reconciliation between BPTs and recalcitrant common beliefs is that their explanation and BPTs can be (or actually are) true together.

Epistemic compatibilism is not based on any form of recarving: a recalcitrant belief that $\phi$ is really a belief that $\phi$ and not some other non-committing mental petent with the vocabulary in $D$, when employing it, are in fact also involved in a pretense,

and then he adds:

Pretense is unquestionably a psychological attitude one bears to content; it is in the same family of attitudes as belief

(Stanley, 2001, p. 4 and p. 13).

"It should be clear that our use of "epistemic compatibilism" has nothing to do with the position under the same name in the debate surrounding doxastic agency. 
state and an ordinary assertion of " $\phi$ " expresses just the proposition that $\phi$. For this reason, an epistemic reconciliation between recalcitrant $\phi$ and BPTs leaves the contrast between BPT and $\phi$ untouched: if BPT is true (and we should assume it is), $\phi$ is a false belief to have. These error-theoretic consequences of epistemic compatibilism are mitigated by the fact that the level of compatibility has now been transferred at a different level: it is not between the belief that $\phi$ and BPT directly, but between an explanation of why it is believed that $\phi$ and BPT.

Let us see how the three forms of compatibilism work in a specific case.

Assume that eliminativism, the view according to which composite middle-sized objects do not exist, is our BPT and that the recalcitrant common belief is that there are chairs (or any other middle-sized artifact in general).

According to semantic compatibilism, the belief that there are chairs in the living room and eliminativism are compatible in case it is shown that an ordinary assertion of "chairs exist" expresses a proposition that is compatible with the nonexistence of middle-sized artifactual objects or, in weaker versions, that an ordinary assertion of "chairs exist" does not clearly express a proposition that is incompatible with the non-existence of chairs.

According to cognitive compatibilism, the belief that there are chairs and eliminativism are compatible in case it is shown that the mental state we are in while thinking about the existence of chairs (or artifacts in general) is a mental state whose commitments are compatible with the non-existence of chairs.

According to epistemic compatibilism, the belief that there are chairs and eliminativism are compatible in case it can be shown that the explanation of why it is believed that there are chairs is compatible with the non-existence of chairs (and of middle-sized artifacts in general).

Our aim in this paper is to show that epistemic compatibilism is the best strategy of reconciliation. Two cautionary observations are in order before we start: (i) here we are more interested in describing the structural features of an 
epistemic reconciliation than in spelling out explicitly the details of an epistemic compatibilist project, and (ii) we are not committed to the view that there is an epistemic reconciliation in any case of conflict between a BPT and a common belief. There may be cases where common beliefs and BPTs are incompatible because there is no way to explain why we believe certain propositions in a way which is compatible with our BPTs. Our point is that, in all those cases where the reconciliation could be effectively carried out, the epistemic version is preferable to its semantic or cognitive one.

We will proceed in the following way. In Sections 2 and 3, we will discuss, respectively, semantic and cognitive compatibilisms and their problems, in Section 4, we are going to present epistemic compatibilism. In the last two sections of the paper, we will discuss the way in which epistemic compatibilism avoids scepticism and the difference between epistemic compatibilism and debunking arguments.

\section{On semantic compatibilism and its problems}

Consider an ordinary assertion of the following sentence:

(1) There are chairs in the next room.

For semantic compatibilists, to interpret the ordinary assertion in 1 as straightforwardly implying the existence of chairs would be hasty. We are often misled by the superficial form of ordinary speech and 1 may be just a case of this.

There are various ways in which this strategy could be developed. ${ }^{6}$ According to what is sometimes called "the traditional method of reconciling paraphrases", to avoid the commitment to chairs, the semantic compatibilist must show that 1 could be paraphrased by another sentence expressing a proposition that does not commit one to the existence of chairs. For example, 1 could be paraphrased along the lines of:

\footnotetext{
${ }^{6}$ For a description of various semantic compatibilist strategies, see, for example, Korman (2016, Ch. 5).
} 
(2) There are some particles arranged chair-wise in the next room.

Thus 2 expresses a proposition perfectly compatible with eliminativism because it commits one just to non-composite entities arranged in a certain way.

The stronger version of the method of reconciling paraphrases has it that 2 gives us an analysis of 1 .

However, there are weaker alternatives: for example, one may claim that while 1 and 2 do not have the same content (one is false, the other is true), 2 is nonetheless a good paraphrase of 1 because 2 can be used "for the same job". An even weaker alternative is one according to which we are not in a position to exclude that the proposition expressed by 1 is the one expressed by 2 .

Semantic compatibilists may appeal to a number of contextual phenomena to defend the view. For example, they may claim that, as uttered in ordinary contexts, the quantifiers in 1 should not be interpreted as joint-carving or fundamental, and so, in such contexts, 1 is not really in contrast with eliminativism. Eliminativism and its consequences should be stated instead using joint-carving or fundamental quantifiers.

Others eliminativists may suggest that an ordinary assertion of 1 is simply a case of loose talk: what speakers really mean by uttering 1 is really something along the lines of 2 . We use 1 as a lazy, idiomatic way of speaking. ${ }^{7}$

A more sophisticated version of semantic compatibilism is the one defended by P. van Inwagen in Material Beings (1990) and other writings. ${ }^{8}$ Here is what he

\footnotetext{
${ }^{7}$ See Thomasson (2007) for loose talk; Lewis (1986, p. 213), Lewis (1991, par. 3.5), Sosa (1999, p. 142), Sider (2004, p. 680) and Richard (2006) for quantifier domain restriction; Dorr (2005, Sec. 7), Chalmers (2009), Cameron (2008, pp. 300-301) and Cameron (2010, p. 256) on the distinction between "joint-carving" and "non-joint-carving" quantifiers; and Horgan and Potrř (2008) for a "contextually operative" semantic notion of truth (see Korman 2008 for a discussion). See also Eklund (2005) for the "indifferentist" strategy, according to which ordinary speakers really do not care about the real content of a sentence like 1.

${ }^{8}$ See also van Inwagen (2014) for a further elaboration. We are here assuming, as does, for example, Merricks (2001), that, in the case of van Inwagen, the thesis that there are no composite artifactual objects, usually called "nihilism", entails the view that there are no ordinary things such as chairs, tables or any macro-physical objects, usually called "eliminativism" (about ordinary, material objects). We are thus attributing to van Inwagen a form of "eliminative nihilism". According to G. Contessa (2014), one could endorse the first thesis without endorsing the second, and he calls this view "non-eliminative nihilism".
} 
wrote in 2014:

In Material Beings I endorsed a meta-ontological position that implies that the sentence "chairs exist" expressed a different proposition in the context I am now calling "the ontology room" from the one it expresses in the context I called "the ordinary business of life".

According to van Inwagen, a sentence like 1, in the context of the "ontology room", is interpreted according to the standards of a "Tarskian language"; thus, it requires for its truth the satisfaction of the propositional function " $x$ is a chair". If eliminativism is our BPT, no single entity could satisfy such a propositional function; thus, 1 expresses a false proposition. However, in ordinary contexts, sentences are not interpreted using a Tarskian language; according to van Inwagen, ordinary speakers "are not only not speaking Tarskian, but are not committed to the 'obvious' translation of their sentences into Tarskian". 9 Thus, the truth of an ordinary use of 1 does not require the satisfaction of the propositional function " $x$ is a chair" and, thus, does not commit us (or, better, it does not commit us for this reason) to the existence of chairs. Actually, nobody knows (or nobody seems to care) what proposition 1 expresses in an ordinary context; what we know, van Inwagen claims, is that in such contexts, 1 expresses a proposition which is necessarily equivalent ("true in exactly the same possible worlds") to a metaphysically neutral proposition. The metaphysically neutral proposition to which 1 is necessarily equivalent to is something along the lines of 2 , which is perfectly compatible with eliminativism. Unlike other forms of semantic compatibilism, according to van Inwagen, the compatible proposition, 2, does not give us the "real content" of 1; 1 and 2 simply express two distinct but necessarily equivalent propositions.

But why be a semantic compatibilist? In particular, why it is so important to "save" recalcitrant commonsense beliefs? This quotation by van Inwagen is especially revealing:

\footnotetext{
${ }^{9}$ van Inwagen $(2014$, p. 7$)$.
} 
Any philosopher who denies what practically everyone believes is, so far as I can see, adopting a position according to which the human capacity for knowing the truth of things is radically defective. And why should he think that his own capacities are the exception to this rule? (van Inwagen, 1990, p. 103)

Here, it is clear that van Inwagen's endorsement of semantic compatibilism is, ultimately, a reaction to the threat of a global form of scepticism: if believed propositions expressed by our ordinary utterances about artifacts come out false, then we cannot exclude that the entire system of "common beliefs formation" is wrong. To avoid global scepticism, the eliminativist needs to "save the phenomena" in a semantic way: ordinary utterances need to come out as true, not simply "acceptable", "useful", "almost true", etc.

We are going to highlight two problems for semantic compatibilism and scepticism:

1. Local scepticism about a certain area of discourse does not necessarily imply a global form of scepticism. The adoption of a semantic form of compatibilism could thus be seen as an overreaction.

2. Semantic compatibilism is itself a potential source of scepticism.

Let us look at the first problem.

A non-compatibilist eliminativist holds that our common beliefs about artifacts are false. If they are false, they cannot be justified or known, so the noncompatibilist eliminativist defends a form of local scepticism about artifacts talk. As we have seen, for van Inwagen, a local form of scepticism about artifacts would drive us towards a global form of scepticism. If our assertions and beliefs about artifacts cannot be known or justified, we should much doubt everything else. What is worse is that global scepticism will also involve the justificational status of our BPTs. If we cannot know "the truth of things", how can we justify the view that, 
for example, eliminativism is our BPT? There has to be a balance between having a revisionist metaphysics like eliminativism and saving (semantically) common sense: common sense needs to be "saved" as soon as we want to save our revisionist metaphysics from the threat of global scepticism.

Within this line of reasoning, van Inwagen (1990) seems to assume that once we conclude a local form of scepticism, this is enough to conclude a global form of it. If we are wrong about artifacts, we might be wrong in all other areas. Local scepticism about artifacts immediately weakens our justifications for all other areas, and thus, global scepticism follows. This line of argument is based on a hidden assumption, and we believe that this assumption is wrong. The assumption is that the reasons that support a local form of scepticism about an area of discourse are transferable to all other areas. However, local scepticisms could have different origins and/or could be the result of different trains of thought; thus, they cannot be "aggregated" to conclude a global form of scepticism.

Scepticism about artifacts talk is motivated by ontological qualms, in particular, qualms about the relation of composition. However, there are other forms of local scepticism that are not based on ontological considerations or are not based on ontological considerations of the same kind. For example, scepticism about mathematical discourse is based on ontological considerations concerning the existence of abstract objects. However, the reasons for being sceptical about the existence of abstract objects have nothing to do with the reasons for being sceptical about the relation of composition for material objects. Therefore, reasons that support local scepticism about artifacts do not support local scepticism about mathematical discourse.

Another similar case is that of morality. Moral scepticism (the view that we cannot know moral truths) is often based on ontological considerations. For example, for J. L. Mackie (1977) there are no moral truths because there are no moral properties, and moral properties do not exist because their postulation would re- 
quire the postulation of "queer" entities such as objective prescriptions. But also in this case, scepticism about queer moral entities seems to be disconnected from scepticism about the relation of composition. Therefore, reasons that support local scepticism about artifacts do not transfer to scepticism about moral discourse.

Finally, there are forms of local scepticism not based on ontological considerations. Take scepticism about meaning, the view that there is no privileged relationship between an expression and what we might be tempted to call its "meaning". According to Kripke (1982), for example, is not a matter of fact whether by "+" we mean the function addition or the function quaddition. This kind of scepticism does not seem to be based on ontological considerations or, at least, on any ontological qualms about the relation of composition. Thus, scepticism about meaning cannot be derived from a local scepticism about artifacts.

A non-compatibilist eliminativist could then associate her local scepticism about artifact talk to a non-sceptical position about mathematical or moral discourse or to a non-sceptical attitude about meaning. Van Inwagen is, therefore, wrong when he claims that a local form of scepticism about middle-sized material objects would imply a global form of scepticism. There seems to be no natural route from local scepticism about middle-sized material objects to global ignorance. Hence, there is no urgency to associate a compatibilist meta-ontological position to a revisionist metaphysics.

Let us now look at the second problem, namely that semantic compatibilism is itself a potential source of scepticism.

Let us start by asking: what does it mean to have an anti-sceptical attitude about artifact talk? Well, a plausible hypothesis is that being anti-sceptical about ordinary existential beliefs about composite objects presupposes a transparent access to the content of such beliefs. This seems to be true in general. For example, to have an anti-sceptical attitude about mathematics presupposes that the content of mathematical propositions is transparent to us. The assertion " $2 \times 3=6$ " (or 
the belief that $2 \times 3=6$ ) is transparent to us if we have access to the proposition it expresses and to its constituents (assuming that propositions are structured entities). If we did not know what proposition is expressed by mathematical assertions we would not say that we know mathematical truths. Transparency is thus a necessary condition to have an anti-sceptical attitude towards a certain area of discourse.

We believe that semantic compatibilism implies a non-transparent access to the content of our beliefs.

Consider a form of semantic compatibilism based on the method of reconciling paraphrases. What the compatibilist typically holds in such cases is that common sense and BPT can be reconciled, if it is possible to show that, for an ordinary assertion expressing a recalcitrant common sense belief, a paraphrase expressing a proposition that is compatible with BPT exists.

However, the mere existence of a paraphrase is not enough. In order to show that common sense is compatible with BPT, the semantic compatibilist should also show that the proposition that the speaker has in mind when uttering the problematic sentence is the one expressed by the paraphrase, not the one prima facie expressed by the paraphrasandum.

In general terms, given an ordinary assertion $\mathrm{S} 1$ that prima facie expresses a proposition in contrast with BPT, the semantic compatibilist has to show two theses, one semantic, the other "psycho-semantic":

1. A paraphrase of $\mathrm{S} 1, \mathrm{~S} 2$, which expresses a proposition compatible with BPT, exists.

2. Speakers who use S1 really wish to express what S2 expresses.

The problem is that a semantic compatibilist is rarely in a position to offer any evidence in favour of the psycho-semantic thesis. Take the case of eliminativism: no ordinary speaker would admit that her ordinary utterances about chairs really 
express propositions about particles disposed chair-wise. In the absence of an appropriate justification for the psycho-semantic thesis, semantic compatibilism entails "semantic blindness", according to which ordinary speakers are not aware of the proposition expressed by their ordinary utterances. They believe in making an assertion about artifacts, but unbeknownst to them, they are really asserting something about X-wise disposed particles. Semantic blindness is a form of nontransparency, so semantic compatibilism implies a non-transparent access to the content of our beliefs and assertions.

The same kind of problem affects more sophisticated versions of semantic compatibilism such as van Inwagen's; as we have seen, van Inwagen (2014, p. 7) does not believe that the proposition that an ordinary speaker is willing to express is the metaphysically neutral proposition. His position is that the proposition expressed in an ordinary context is different from the metaphysically neutral proposition, even though it is necessarily equivalent to it. The problem, however, is that the ordinary speaker is not aware that the same utterance can express two different propositions in different contexts. She is not aware that "chairs exist" should receive a Tarskian interpretation in theoretical contexts and a different interpretation in ordinary contexts. Actually, no ordinary speaker really seems to care about it. We are thus in a situation where an ordinary speaker utters 1 in an ordinary context without exactly knowing what proposition is really expressed. Even this kind of semantic unawareness is a form of semantic blindness that brings with it non-transparency and, in the end, scepticism.

\section{On cognitive compatibilism and its problems}

A cognitive compatibilist is one who claims that the apparent ontological commitments of a certain area of discourse should not be taken literally, because when we are engaged in such a discourse, we are engaged in a pretense.

For the cognitive compatibilist, when we say something like "there are prime 
numbers", we are not literally believing that there are prime numbers (even though the content we are entertaining is that there are prime numbers), but we are in a peculiar mental state $C$ such that $C(\ulcorner$ there are prime numbers $\urcorner)$ does not commit us to the the existence of prime numbers. Being in such a mental state, the cognitive compatibilist argues, is the same epistemic state we are in when we are playing games of make-believe or grasping figurative language. ${ }^{10}$ On this basis, the cognitive compatibilist could claim, for example, that our common beliefs about numbers and our best nominalistic theories could be reconciled because when we think that there are numbers, we are not really expressing our belief in the existence of numbers, but our make-belief in the existence of numbers, and our make-belief that there are numbers does not commit us to the existence of numbers.

In the same manner, eliminativism could be cognitively reconciled with the common belief that there are chairs, if it can be shown that we are not really believing that there are chairs, but only make-believing that there are chairs, that our chair talking, and, in general, our artifact talking, is fictional, i.e. we are engaged in a pretense.

As the semantic compatibilist aims to show that an ordinary utterance of " $\phi$ " really expresses a proposition that is compatible with $\mathrm{BPT}$, the cognitive compatibilist aims to show that the mental state $\operatorname{Bel}(\ulcorner\phi\urcorner)$ really is a mental state whose commitments are compatible with BPT. For the eliminativist who is also a semantic compatibilist, we are not really expressing the proposition that there are chairs while uttering, in an ordinary context, "there are chairs"; for the eliminativist who is also a cognitive compatibilist, the mental state we are in while uttering "there are chairs" in an ordinary context is not a belief.

We are now going to highlight two problems for cognitive compatibilism.

The first is that, in order to be a cognitive compatibilist about a certain area of discourse, it has to be shown that we are in a peculiar mental state when we

\footnotetext{
${ }^{10}$ Cfr. Walton (1990).
} 
are engaged in a discourse belonging to such an area or that such an area exhibits some similarities with figurative speech. This might be easy for fictional discourse, more difficult for mathematical discourse and very difficult in the case of artifact talk.

An eliminativist who is also a cognitive compatibilist should show that when we are speaking about chairs we are, unbeknownst to us, in a very peculiar mental state, the one we are in when we are engaged in a pretense. Admittedly, this is problematic and particularly implausible for the case of artifact talk. What would be the evidence? There seems to be no "feeling of non-literality" associated with artifact talk and no clear metaphorical element associated with it.

According to Yablo (2000), there are some "phenomenological features" associated with a discourse that exhibits fictional features. These phenomenological features should be recognised by ordinary speakers in ordinary uses. For example, a certain form of indeterminacy is associated with a discourse of such a kind: within a pretense, it makes partly no sense to ask for determinate identity relations because it is left partly undecided what is to count as identical to what. However, no ordinary speaker would consider meaningless the question of whether the chair I was speaking about yesterday is the same one that I am speaking about today. At least not in the same way as she would consider meaningless the question whether the fuse I blew last week is the same one I blew today. The same seems to hold for other phenomenological features that Yablo individuates, for example, impatience. Within a pretense, we are impatient with literalists who want us to worry that a fictional character does not exist ("Sherlock Holmes is a detective, but of course Sherlock Holmes does not exist"). The same does not happen within discourse about artifacts: the reaction we would have is not impatience (or at least not the same kind of impatience) in case someone utters something like "The are two chairs in the other room, but, of course, chairs do not exist". Silliness is another feature of fictional discourse that artifact talk seems to lack. According to Yablo (2000, 


\footnotetext{
${ }^{11}$ The same seems to be true for all features that Yablo individuates (expressiveness, disconnectedness, availability, etc.).
} how big the average star is. Where is it located?". The same phenomenon seems to be absent in ordinary discourses about artifacts: a question like "We know how big the chair in the other room is. Where it is located?" does not sound silly at all. ${ }^{11}$

While failure of artifact talk to satisfy some or all items in Yablo's list should not be taken as decisive, it is at least revelatory that the cognitive compatibilist should offer us more than a hint to prove that the cognitive attitude we have while engaged in artifact talk is pretense.

The second problem is related to scepticism. As we have seen in the previous section, semantic compatibilism, while designed to be a response to sceptical worries, is itself a source of a sceptical attitude. The reason is that semantic compatibilism is based on a non-transparent access to the content of our beliefs.

Cognitive compatibilism scores no better in this respect because it is based on a non-transparent access not to the content but to the identity of our mental states.

For the cognitive compatibilist, a reconciliation between BPT and a recalcitrant belief of an agent could be obtained only upon the condition of showing that the mental state the agent is in is not really belief. However, competent speakers quite certainly would deny that they are engaged in a pretense while thinking or speaking about artifacts. Cognitive compatibilists would then be forced to assume that ordinary speakers are pretending without knowing it; they confuse makebelief with plain belief. As Stanley (2001, p. 126) emphasises, this implies a "quite drastic form of failure of first-person authority over one's own mental states".

While semantic compatibilism entails a loss of first-person authority about the content of one's psychological attitude, cognitive compatibilism entails a loss of first-person authority about the identity of one's own psychological attitude. This is a form of "cognitive blindness" that, exactly like semantic blindness in the case

p. 259), fictional discourse invites "silly" questions about their objects: "We know 
of semantic compatibilism, entails a sceptical attitude.

Therefore, exactly like semantic compatibilism, cognitive compatibilism is a self-defeating strategy of reconciliation between BPTs and recalcitrant common beliefs and assertions.

\section{Epistemic compatibilism}

For epistemic compatibilism, the view we are presenting and defending in this paper, there is no need to semantically recarve the proposition expressed by an ordinary assertion of " $\phi$ " or to cognitively recarve the mental attitude we have towards the proposition expressed by " $\phi$ ". To obtain a good reconciliation between $\phi$ and BPT, it is enough that the explanation to believe that $\phi$ does not conflict with BPT.

Using $\left\ulcorner\phi^{*}\right\urcorner$ as the proposition, which for an s-compatibilist is "really" expressed by an ordinary utterance of " $\phi$ ", using $\operatorname{Bel}^{*}(\ulcorner\phi\urcorner)$ as the mental state, which for a c-compatibilist a subject is really in when (having the impression of) believing that $\phi$, and using $\operatorname{Exp}(\operatorname{Bel}(\ulcorner\phi\urcorner))$ as an explanation of why it is commonly believed that $\phi$, we could represent the different kinds of compatibilism by the following table:

\begin{tabular}{lll}
\hline s-compatibilism: & BPT is s-compatible with $\quad\left\ulcorner\phi^{*\urcorner}\right.$ \\
c-compatibilism: & BPT is c-compatible with $\quad \operatorname{Bel}^{*}(\ulcorner\phi\urcorner)$ \\
e-compatibilism: & BPT is e-compatible with $\quad \operatorname{Exp}(\operatorname{Bel}(\ulcorner\phi\urcorner))$ \\
\hline
\end{tabular}

As the table clarifies, epistemic compatibilism is the only strategy of reconciliation not based on any form of recarving, neither semantic (the proposition is the one prima facie expressed by an ordinary utterance of " $\phi$ ") nor cognitive (the mental state to be explained is just belief). Notice that it follows from the definition of epistemic compatibilism, given on page 5 , that the e-compatibility of BPT and $\operatorname{Exp}(\operatorname{Bel}(\ulcorner\phi\urcorner))$ simply amounts to the requirement that BPT and $\operatorname{Exp}(\operatorname{Bel}(\ulcorner\phi\urcorner))$ are true together. 
Now, let us recall the schematic argument by which BPT and $\phi$ are declared incompatible:

(Dis) 1. According to BPT, $\psi$

2. It is commonly believed that $\phi$

3. $\ulcorner\psi\urcorner$ and $\ulcorner\phi\urcorner$ are inconsistent

4. Therefore: BPT and the common belief that $\phi$ are incompatible

The aim of any compatibilism (be it semantical, cognitive or epistemic) is to show that the conclusion does not follow.

For epistemic compatibilism, the argument does not follow because it relies on a wrong conception of incompatibility between BPT and a belief: from the fact that BPT and our beliefs have inconsistent propositional content, it does not follow that they are incompatible. A theory and a belief can have inconsistent propositional content and be compatible nonetheless.

To show that a theory and a belief are incompatible, we need to show that the explanation of why we have such a belief cannot be true together with BPT. If we have such an explanation, BPT and the belief are compatible.

To have a sense of how epistemic compatibilism might work, consider this example (adapted from a famous example of van Inwagen and used for our purposes): Copernican cosmological theories conflict with the common belief that the Sun is moving across the sky. But, as it happens, we have a very good explanation for the tendency to form this belief in creatures like us. The belief originates from our impression of seeing the Sun moving, and this impression depends on our position (we live on the Earth) and on the effects on our cognitive systems of the Earth rotating around its axis and orbiting around the Sun.

Once we have this explanation at hand, the belief that the Sun is moving seems to be reconciled with our Copernican cosmological theory. This is because not only are we able to explain that the propositional content of the belief is false, but more 
importantly for the reconciliation we have an explanation of why we tend to form such a belief, couched in a theory that does not presuppose that the Sun is moving. An astronomer trying to explain why we tend to form the belief that the Sun is moving would consider it very strange (or she might say, very "philosophical") to say that when we believe that the Sun is moving, we are not really believing that the Sun is moving, but we are really having a belief about the axis of the Earth. Or, even more strangely, that we are not really believing that the Sun is moving across the sky, but only make-believe it. Having produced an explanation of the tendency to form such a belief, the astronomer makes the belief somewhat "reasonable" in the sense of being explainable in a way compatible with our best theory, even though it is false. A belief that is reasonable in this sense, with respect to a theory $T$, is reconciled with $T .{ }^{12}$

Our position is that reconciliations between theories and common recalcitrant beliefs should be construed along this model, which is not the model of s-compatibilism or c-compatibilism, and it is the model often used in scientific contexts when a common belief conflicts with our best theories of the physical world.

Let us see how epistemic compatibilism works in the case of eliminativism. Eliminativism and common beliefs about the middle-sized artifacts are reconciled (if they can be reconciled at all) in case it is shown that the explanation of why it is commonly believed that, for example, there are chairs is compatible with eliminativism. In the best case scenario, what would have to be shown is that the explanation of the common belief does not actually contradict eliminativism.

Eliminativism and $\operatorname{Expl}(\operatorname{Bel}(\ulcorner$ there are chairs $\urcorner)$ are thus reconciled, if it is shown that $\operatorname{Expl}(\operatorname{Bel}(\ulcorner$ there are chairs $\urcorner)$ does not imply the existence of chairs

\footnotetext{
${ }^{12}$ One may be worried that even the tendency to believe that the Earth is flat comes out as "reasonable" in the sense defined above. No panic! This should not be taken as evidence in favour of such a crazy view. On the contrary, it would simply mean that we could perfectly explain the false belief that the Earth is flat in terms of the best physical theory, according to which the Earth is not flat. In effect, a good line of response to "flatearthists" would just be to point out that all the phenomenological evidence in favour of their view may receive a perfectly good explanation in orthodox science that plainly contradicts it. If the belief that the Earth is flat is epistemically reconciled with our best physical theories, then "flatearthism" is false.
} 
and middle-sized artifacts, in general, or say the same thing with other words, if it is shown that the existence of chairs is dispensable from the explanation of the common tendency to believe in chairs. We can thus reformulate epistemic compatibilism in such terms:

Epistemic compatibilism: BPT and $\phi$ are reconciled if it is shown that the truth of $\phi$ is dispensable from $\operatorname{Exp}(\operatorname{Bel}(\ulcorner\phi\urcorner))$.

Assume that we have at our disposal an explanation of why it is believed that there are chairs from which the existence of chairs is not dispensable. Assume, for example, that the psychological explanation of our tendency to perceive (and, consequently, to believe in the existence of) middle-sized objects such as chairs is expressed within a theory, committing us to the existence of chairs or composite objects in general. This would be a situation where our BPT, i.e., eliminativism, and our psychological theory are in contrast. One way to describe this conflict is to say that the ontological commitments of our psychological theory are not compatible with those of our BPT.

What should be done in this kind of cases? Well, it depends on the overall meta-theoretical situation. If we have meta-theoretical reasons - having to do with simplicity, predictivity, systematicity, etc. - to believe that our psychological theory is more "robust" than our BPT, then we should abandon our BPT, i.e. eliminativism. This would be simply a case where the reconciliation between BPT and our beliefs cannot be done.

But if we have meta-theoretical reasons to stick to our BPT, one way to solve the issue would be to try to reformulate our psychological theory in a way that makes it compatible with our BPT. Epistemic reconciliation can thus be seen as the reconciliation between two theories: our BPT and the theory in terms of which we explain our recalcitrant beliefs. ${ }^{13}$

\footnotetext{
${ }^{13}$ Even in the case of s-compatibilism, the contrast between $\phi$ and BPT could as well be understood as a contrast between two theories, namely our BPT and our semantic theory for $\phi$.
} 
Notice two things, however. The first: the case in which we try to reformulate the theory that explains our beliefs in a way compatible with our BPT should not be seen as the manifestation of a general requirement that scientific or nonphilosophical theories should be made compatible with philosophical ones (it may happen sometimes, but it should not be a forced choice). In our case, we are simply trying to reformulate a theory in a way that makes its ontological commitments compatible with our BPT. To use an analogy: a nominalistic reconstruction of mathematics (where nominalism is our BPT) is not a way in which nominalism "influence" mathematics, but a way in which the ontological commitments of mathematics are made compatible with nominalism. It is a form of "rewriting" rather than a form of "influencing". ${ }^{14}$ Second, the eventual requirement to reformulate a psychological theory (or whatever theory we need to use to explain a recalcitrant belief) in order for it to be compatible with BPT should not be counted as a form of "recarving", at least not in the way in which we have defined it above: semantic and cognitive recarving are "operations" done on the recalcitrant belief $\phi$. Semantic recarving recarves the content of $\phi$ while cognitive recarving recarves the cognitive status of the belief that $\phi$. The eventual reformulation of a theory in order for it to be compatible with our BPT is instead just a manifestation of the common theoretic attitude of making a theory compatible with what we believe is our best theory, something that should be done in any case. The content of $\phi$ or its cognitive status are left untouched. For epistemic compatibilism, the common belief that there are chairs is just the (false) belief that there are chairs. It is reconciled with eliminativism in case it is shown, for example, that the tendency to believe in the existence of composite objects is just some sort of psychological bias.

The contrast is solved exactly as it would happen in the case of e-compatibilism if it is shown that our semantic theory is made compatible with our BPT, and if it could generate semantic analyses of $\phi$ that are compatible with BPT. If you are an eliminativist, then it is better if your semantic theory is compatible with eliminativism.

${ }^{14} \mathrm{We}$ would like to thank a referee of Inquiry to press us on this point. For a discussion of nominalistic reconstructions, see Chihara (2005). For a critique of this kind of (revolutionary) forms of nominalism, see Burgess and Rosen (1997). 
However, a psychological theory for which the tendency to believe in composite objects is a bias will presumably not have composite objects in its ontology, so it will be compatible with eliminativism. ${ }^{15}$

One might wonder whether an epistemic reconciliation is too weak. After all, a semantic reconciliation seems to be more "robust" than an epistemic reconciliation. At the end of the process of semantic reconciliation, the proposition expressed by " $\phi$ " is true together with BPT and what " $\phi$ " expresses is no more recalcitrant. Instead, at the end of the process of epistemic reconciliation, what " $\phi$ " expresses remains recalcitrant and what we have in our hands is "simply" an explanation of why it is believed that $\phi$, which is compatible with BPT. Is this enough to conclude that BPT and the recalcitrant belief are thus reconciled? Surely not, if reconciliation requires consistency of propositional content. But, and this is the point, not all reconciliations need to be semantical in this sense.

To evaluate which type of reconciliation is more adequate, we should ask ourselves the following question: why are we looking for a reconciliation between BPT and our recalcitrant common beliefs in the first place? As mentioned in the introduction, one reason to look for a reconciliation between BPT and $\phi$, actually the main one, is to preserve the role of $\phi$ as a common belief. So, let us check how the "commonality" of $\phi$ is preserved under the two kinds of compatibilism.

Which account better explains the role of $\phi$ as a common belief?

We think that the "doxastic reconstruction" offered by epistemic compatibilism, appearances notwithstanding, is better placed than the semantic reconstruction offered by semantic compatibilism to account for $\phi$ 's role as a common belief.

Under semantic compatibilism, the existence of a paraphrase of " $\phi$ " that makes it compatible with BPT does nothing to explain the role of $\phi$ as a common belief. The reasoning seems to be: given that the belief that $\phi$ is common, it needs to be "saved" by associating an ordinary utterance of " $\phi$ " with a paraphrase that

\footnotetext{
${ }^{15}$ We would like to thank a referee of Inquiry for pointing us to this potential ambiguity between recarving a belief and reformulating the theory that explains a belief.
} 
expresses a proposition compatible with BPT. However, this reasoning simply assumes that the belief that $\phi$ is common does not explain it.

Epistemic compatibilism, in contrast, is able to preserve and justify the "commonality" of $\phi$. An explanation of the tendency to believe $\phi$ just is an explanation of why $\phi$ is common: reconstructing the doxastic genealogy of $\phi$ is also to explain the particular role that $\phi$ has in our system of beliefs.

Epistemic compatibilism, unlike semantic compatibilism, is thus able to offer an explanation of $\phi$ 's role as a common belief. Epistemic reconciliation, far from being a weak reconciliation, is better placed than semantic reconciliation to explain the commonality of $\phi$ and thus to reconcile $\phi$ with BPT.

In the next two subsections, we will specify further the main features of epistemic compatibilism by discussing: (i) the way in which it avoids scepticism, and finally, (ii) the differences between an epistemic reconciliation and a debunking argument.

\subsection{Epistemic compatibilism and scepticism}

One may wonder whether epistemic compatibilism fares better than semantic and cognitive compatibilism with respect to scepticism. After all, if there is an epistemic reconciliation between $\phi$ and $\mathrm{BPT}$, we are in a situation where $\operatorname{Exp}(\operatorname{Bel}(\ulcorner\phi\urcorner))$ and BPT are true together and $\phi$ is false; namely, a situation where we have epistemic reconciliation and a falsity of recalcitrant common beliefs. However, if common beliefs come out false, then, to use van Inwagen's words again, "[the] capacity to know the truth of things is radically defective". ${ }^{16}$ So, generalised scepticism seems to represent a threat also for epistemic compatibilism.

Against this sceptical challenge, we can respond in two ways.

On the one hand, as we have already shown, local error theory about a certain area of discourse does not imply any form of generalised scepticism. So, we may

\footnotetext{
${ }^{16}$ van Inwagen (1990, p. 103).
} 
conclude that all common beliefs for a certain area of discourse are false without this implying that the capacity to know the truth of things is "radically defective"; it is defective only with respect to that area. Surely, an epistemic reconciliation of our common beliefs about chairs with eliminativism implies that common beliefs about chairs are false, but this does not imply that all other common beliefs (or simply all other existential common beliefs) are false. As we have seen, this is compatible with our capacity to know moral, mathematical or semantical truths.

On the other hand, an epistemic reconciliation does not leave us with only an explanation of the falsity of some common beliefs: what an epistemic reconciliation offers us is an explanation of why there is a tendency to have such beliefs. The falsity of the common beliefs belonging to this area is thus coupled with an explanation of why there is the tendency to have such beliefs, and this prevents the local scepticism with respect to an area to expand into other areas or to be philosophically "out of control".

As we have seen, one of the problems of semantic compatibilism is the lack of any plausible justification of the relationship between the proposition that " $\phi$ " expresses prima facie in ordinary contexts and its recarved version. The same holds for cognitive compatibilism: it is sometimes very difficult to justify the view that the mental states the agents are supposed to be in while thinking the recalcitrant content are those postulated by cognitive compatibilists. In the case of artifacts, as we have seen, we simply do not have any evidence that we are engaged in a fictional discourse when talking and thinking about artifacts. The relationship between $\phi$ or the belief that $\phi$ and their recarved versions are thus at risk of being arbitrary under both semantic and cognitive compatibilism.

Epistemic compatibilism does not have this problem: we have epistemic reconciliation if and only if we have an explanation of the tendency to believe that $\phi$. The explanations that epistemic compatibilism offers us are thus both nonarbitrary and true. Non-arbitrary because they are explanations just of those 
recalcitrant beliefs and true because an explanation of a recalcitrant belief that $\phi$ has the same truth value of our BPT.

The epistemic situation where an epistemic reconciliation leaves us is thus not at risk of being sceptical: we are not in a situation where we do not know whether some common beliefs are true or false or where we do not know what their content is or what the real nature is of the mental state we are in while thinking them. Rather, we are in a situation where we know that they are false, and more importantly where we have an explanation of their falsity that is compatible with our BPT.

\subsection{Epistemic compatibilism and debunking}

One might wonder whether epistemic compatibilism has something in common with debunking arguments. ${ }^{17}$

In the moral case, a debunking argument proceeds as follows: from the assumption that our moral beliefs or dispositions are shaped by natural selection and given that natural selection shaped our moral beliefs to favour biological fitness rather than to track moral truths, the debunker concludes that there is not an explanatory connection between moral beliefs and a supposed moral reality; thus, that we should abandon moral beliefs.

Essential elements of a debunking argument are:

- a (usually empirical) claim about the origin of certain beliefs;

- a claim about the absence of an explanatory connection between such beliefs and the facts these beliefs are about.

Based on such elements, a debunking argument about our beliefs in the existence of chairs would be something along the following lines:

\footnotetext{
${ }^{17}$ Cf. Korman (2016, Ch. 7), Benovsky (2015), Merricks (2001), and White (2010); for debunking arguments in the context of discussions about moral realism, see Bedke (2009), Joyce (2007), Kitcher (2007), Shafer-Landau (2012), and Vavova (2015).
} 
- the origin of common beliefs about chairs does not depend on the existence of chairs (common beliefs about chairs do not track the existence of chairs);

- thus, there is no explanatory connection between common beliefs about chairs and the existence of chairs;

- if so, then we should not believe that there are chairs;

- therefore: we should not believe that there are chairs.

In effect, epistemic compatibilism (assuming that eliminativism is our BPT) seems to be committed to very similar views. An epistemic compatibilist would, in fact, subscribe to the following theses:

- there is an explanation of the common beliefs that there are chairs (and eventually an explanation of their origin);

- this explanation does not depend on the existence of chairs;

- there is no explanatory connection between the existence of chairs and existential beliefs about chairs. Chairs do not exist, so chairs cannot explain anything.

However, debunking arguments are typically anti-compatibilist arguments, because to debank a recalcitrant belief that $\phi$ is, typically, to conclude that we should abandon such a belief. So, if one is a debunker with respect to $\phi$, one is surely not willing to reconcile $\phi$ with BPT. On the contrary, the epistemic compatibilist is a compatibilist and compatibilism's most relevant aim, as we have seen, is to preserve the status of common beliefs. From the claim that the origin about our beliefs about chairs is not related to the existence of chairs, the epistemic compatibilist, unlike the debunker, does not conclude that the source of such common beliefs is disreputable and, thus, that having beliefs about chairs is somewhat "irrational". On the contrary, the epistemic compatibilist claims that, given that beliefs about 
middle-sized artifacts are common, they need to be explained in a way which is compatible with our BPT, namely eliminativism.

The aim of a compatibilist (be it semantic, cognitive or epistemic) is to be be conservative with respect to common beliefs, even in the face of our preferred revisionary metaphysical theory. The result of a debunking argument is instead revolutionary: some common beliefs (the common belief that there are chairs) have to go, and we need to heavily reconceptualize our or others mental life to do without them ("no more beliefs about chairs!" says the eliminativist debunker).

The result of epistemic reconciliation is not "revolutionary"; the status of our common beliefs qua common beliefs is preserved, and it is preserved just because we have found a good explanation for the tendency to have such beliefs, which is compatible with our philosophical preferences. But then, according to the epistemic compatibilist, there is no need to reconceptualize our mental life, no need for a massive clean-up of our deteriorated beliefs.

Finally, the debunker and the epistemic compatibilist are modally orthogonal: the aim of the debunker is to explain what should be believed; the aim of the epistemic compatibilist is to explain what is actually believed; for the debunker what others actually believe should simply be dismissed; for the epistemic compatibilist, it can be saved if it can be explained in accordance with our BPTs.

\section{Conclusions}

In this paper, we have presented a new strategy of reconciliation between common beliefs and BPTs: epistemic compatibilism. We have claimed that such a strategy of reconciliation should be preferred to semantic and cognitive flavours of compatibilism as far as each of these strategies is based on a peculiar form of "recarving". We have claimed that reliance on recarving (semantic or cognitive) is at the origin of a potential sceptical attitude that, ironically enough, was the main motivation for choosing a compatibilist stance in the first place. Semantic and 
cognitive compatibilism are, therefore, self-defeating forms of compatibilism, and, if one wants to preserve a compatibilist attitude at all, epistemic compatibilism should be preferred.

Epistemic compatibilism does not have such sceptical consequences because it is not based on any form of recarving. According to the epistemic compatibilist, a recalcitrant belief that $\phi$ has the content it apparently has and it is the mental state it apparently is. Rather, to have an epistemic reconciliation between recalcitrant beliefs and BPTs, an explanation of why someone has such a belief compatible with our BPT is required.

In case we have an epistemic reconciliation between a recalcitrant belief $\phi$ and our BPT, $\phi$ is still recalcitrant and thus false. But then, common existential beliefs about artifacts are false, and this might appear as another manifestation of a sceptical threat. We have defended the claim that this is not the case: after an epistemic reconciliation, we conclude that recalcitrant beliefs are false, but this is not done in isolation. We now have also an explanation of why there is a tendency to have these kind of beliefs, and this, we have argued, is enough to save epistemic compatibilism from the threat of scepticism.

Acknowledgements Various versions of this paper has been presented at the PRIN National conference "Realism and Objectivity" (Matera, 2015), the research seminar in theoretical philosophy (Bielefeld, 2015), the XII SIFA National Conference (Pistoia, 2016), the conference "Science, Philosophy and Common Sense" (Amsterdam, 2016) and the workshop "The Metaphysics of Ordinary Objects" (Pisa, 2016). We would like to thank all the participants for their useful comments and suggestions. Many thanks also to Ciro De Florio, Daniel Korman, Giorgio Lando, Christian Nimtz, and the referees of Inquiry. 


\section{References}

Bedke, M. (2009). Intuitive non-naturalism meets cosmic coincidenc. In R. ShaferLandau (Ed.), Oxford studies in metaethics (Vol. 9, pp. 102-25). Oxford University Press.

Benovsky, J. (2015). From experience to metaphysics. Nô̂s, 49, 684-697.

Burgess, J. (1983). Why I am not a nominalist. Notre Dame Journal of Formal Logic, $24(93-105)$.

Burgess, J., \& Rosen, G. (1997). A subject with no object: Strategies for nominalistic interpretation of mathematics. Oxford: Clarendon Press.

Cameron, R. (2008). There are no things that are music works. British Journal of Aesthetics, 48, 295-314.

Cameron, R. (2010). How to have a radically minimal ontology. Philosophical Studies, 151, 249-264.

Chalmers, D. (2009). Ontological anti-realism. In D. Chalmers, D. Manley, \& R. Wasserman (Eds.), Metametaphysics (pp. 77-129). Oxford: Oxford University Press.

Chihara, C. S. (2005). Nominalism. In S. Shapiro (Ed.), Oxford handbook of the philosophy of mathematics and logic (pp. 483-514). Oxford: Oxford University Press.

Contessa, G. (2014). One's a crowd: Mereological nihilism without ordinary-object eliminativism. Analytic Philosophy, 55(2), 199-221.

Dorr, C. (2005). What we disagree about when we disagree about ontology. In M. Kalderon (Ed.), Fictionalism in metaphysics (pp. 32-63). Oxford: Clarendon Press.

Eklund, M. (2005). Fiction, indifference and ontology. Philosophy and Phenomenological Research, 71, 557-579.

Horgan, T., \& Potrř, M. (2008). Austere realism. Cambridge MA: The MIT Press. Joyce, R. (2007). The evolution of morality. Cambridge: Cambridge University 
Press.

Kalderon, M. (2005). Moral fictionalism. Oxford: Clarendon Press.

Kennedy, C., \& Stanley, J. (2009). On average. Mind, 118, 583-646.

Kitcher, P. (2007). Biology and ethics. In D. Copp (Ed.), The Oxford handbook of ethical theory (pp. 163-185). Oxford: Oxford University Press.

Korman, D. (2008). Review of Austere Realism. Notre Dame Philosophical Reviews.

Korman, D. (2016). Ordinary objects. Oxford University Press.

Kripke, S. (1982). Wittgenstein on rules and private language. Harvard University Press.

Lewis, D. K. (1986). On the plurality of worlds. London: Routledge.

Lewis, D. K. (1991). Parts of classes. Oxford: Blackwell.

Mackie, J. L. (1977). Ethics: Inventing right and wrong. Harmondsworth: Penguin.

Merricks, T. (2001). Objects and persons. Oxford: Clarendon Press.

O’Leary Hawthorne, J., \& Michaelis, M. (1996). Compatibilist semantics in metaphysics: A case study. Australasian Journal of Philosophy, 74, 117-134.

Quine, W. v. O. (1948). On what there is. Review of Metaphysics, 2(21-38).

Richard, M. (2006). Context, vagueness and ontology. In P. Greenough \& M. Lynch (Eds.), Truth and realism. Oxford University Press.

Shafer-Landau, R. (2012). Evolutionary debunking, moral realism and moral knowledge. Journal of Ethics and Social Philosophy, 7, 1-37.

Sider, T. (2004). Reply to Gallois, Hirsh and Markosian. Philosophy and Phenomenological Research, 58, 674-687.

Sosa, E. (1999). Existential relativity. Midwest Studies in Philosophy, 23, 132-143.

Stanley, J. (2001). Hermeneutic fictionalism. Midwest Studies in Philosophy, 25, $36-71$.

Thomasson, A. L. (2007). Ordinary objects. Oxford: Oxford University Press. 
van Inwagen, P. (1990). Material beings. Ithaca, NY: Cornell University Press.

van Inwagen, P. (2014). Introduction: inside and outside the ontology room. In Existence: essays in ontology (pp. 1-14). Cambridge University Press.

Vavova, K. (2015). Evolutionary debunking of moral realism. Philosophy Compass, $10,104-116$.

Walton, K. (1990). Mimesis as make-believe. Cambridge MA: Harvard University Press.

White, R. (2010). You just believe that because. Philosophical Perspectives, 24, $573-615$.

Yablo, S. (1998). Does ontology rest on a mistake? Aristotelian Society Supplementary Volume, 72, 229-283.

Yablo, S. (2000). Textbook Kripkeanism and the open texture of concepts. Pacific Philosophical Quarterly, 81, 98-122.

Yablo, S. (2001). Go figure: A path through fictionalism. Midwest Studies in Philosophy, 25, 72-102. 